\title{
Optimization and Kinetics of the Solid-liquid Extraction Process of Polyphenols from Black Mulberry Fruit
}

\author{
EMILIJ A KOSTIC ${ }^{2 *}$, GORAN M. NIKO LIC ${ }^{2}$, SNEZANA MITIC ${ }^{1}$, DANICA DIMITRIJ EVIC ${ }^{1}$, MILAN MITIC ${ }^{1}$ \\ 'Department of Chemistry, Faculty of Sciences and Mathematics, University of Nis, Nis, Serbia \\ 2Faculty of medicine, University of Nish, Serbia
}

\begin{abstract}
This paper investigates the influence of operating conditions and extraction techniques (maceration and ultrasonic) on the yield and extraction of dry extract, total phenolic, flavonoids and anthocyanins from black mulberry fruit (Morus nigra L.). The optimal extraction conditions and kinetic parameters of the extraction process are determined.
\end{abstract}

Keywords: extraction, Morus nigra L., optimal condition, kinetic parametrs

Genus Morus is widespread in Asia, Europe, North and South America and Africa. Mulberry is located in the temperate and sub-tropical regions of the northern hemisphere [1-3]. Black mulberry is quite widespread in the area of Serbia. The black mulberry is found to be especially rich in anthocyanins, flavonoid and phenol compounds [4-8]. The total content of these compounds are dependent on geographic location, soil on which the mulberry tree grows, type of extraction, length of extraction, type of solvent. Mulberry has a unique delicious fruit, sour and refreshing taste. It has been used as a folk remedy to treat oral and dental diseases, diabetes, hypertension, arthritis and anemia [2, 9]. The bright black mulberry fruits, which have a very pleasant taste when eaten fresh, are also used in jams, juices, liquors, natural dyes as well as in the cosmetics industry $[3,10]$. In earlier studies of the extraction kinetics using different techniques it was found that higher yields are achieved circulation techniques in relation to the maceration. It was found that the operating conditions have an impact on the extraction yield and the kinetics of extraction [11-14].

In the literature, there are no available data on the kinetics of extraction from water-ethanol extracts of black mulberry fruit, nor of the extraction efficiency and the impact of various extraction tehniques on yield and composition of water-ethanol extracts from mulberry fruit. The black mulberry and its extracts can be used as a good source of natural plant pigment and antioxidant agents. The aim of this work is that on the basis of comparative tests yield and extraction kinetics maceration and ultrasonic extraction define the optimal extraction technique which achives maximum yields phenolic compounds and determine the parameters in the extraction kinetics equations. The optimum conditions for extraction of phenolic compounds from black mulberry fruit were selected by examining the influence of ethanol concentration, time and extraction method.

\section{Experimental part}

The plant material was collected in South-East Serbia in early J uly 2013. Fruit maturity was estimated on the basis of the color which was very black.

Maceration: Measured the mass (10 g) previously homogenized fruit blender dummy. Triturated and homogenized fresh mulberry fruit $(10 \mathrm{~g})$ was coated with a mixture previously prepared solvent: ethanol-water- $\mathrm{HCl}$ (20:79:1), ethanol-water- $\mathrm{HCl}(40: 59: 1)$, ethanol-water- $\mathrm{HCl}$
$(60: 39: 1)$ and ethanol-water- $\mathrm{HCl}(80: 19: 1)$ at a ratio of 1:10 w / v. Maceration with a solvent system of each was performed at 15, 30,60, 120 or $240 \mathrm{~min}$ at a temperature value of $25^{\circ} \mathrm{C}$. The suspension was then filtered through a Buchner funnel and Whatman No.1 filter paper. The extracts were stored in the refrigerator and in the dark to their use for the determination of phenolic compounds [ 15 , $16]$.

Ultrasonic extraction: Milled plant material $(10 \mathrm{~g})$ was extracted previously mentioned systems ethanol aqueous solvent, the solvomodulu $1: 10 \mathrm{~m} / \mathrm{v}$ thermostatted ultrasonic bath (Sonic, Nis, Serbia; nominal power: $3 \times 50$ $W$; dimensions of bathrooms: $30 \times 15 \times 20 \mathrm{~cm}$ ) at a frequency of $40 \mathrm{kHz}$. The kinetics of extraction of phenolic compounds at the indicated time intervals (15-240 minutes). The extracts were separated from the plant material on Bichner's funnel with a weak vacuum and further treated according to the procedure for the determination of total phenols [17].

Aparats and reagents: The Folin-Ciocalteu phenol reagent and sodium carbonate were purchased from Merck Chemical Suppliers (Darmstadt, Germany). Sodium chlorate buffer ( $p \mathrm{H}$ 1.0) and acetate buffer ( $p H$ 4.5) were purchased from the same producer.

The other used chemicals including solvents were of analytical grade. An Agilent 8453 UV-vis. spectrophotometer was used for absorbance measurements and spectra recording, using an optical or quartz cuvettes of 1$\mathrm{cm}$ optical path. The $\mathrm{pH}$ measurements were made with Hanna Instruments $\mathrm{pH}$-meter equipped with glass electrode.

Determination of total phenolics: Total phenol contents of the extracts were determined by the modified FolinCiocalteu method [14]. An aliquot of the extracts $(1 \mathrm{~mL})$ was mixed with $0.5 \mathrm{~mL}$ Folin-Ciocalteu reagent and $2 \mathrm{~mL}$ of sodium carbonate (20\%). Absorbance was measured after 10-min incubation at room temperature at $760 \mathrm{~nm}$. Total phenolic content was expressed as $\mathrm{mg} / 100 \mathrm{~g}$ gallic acid equivalent (GAE). The result of each one assay was obtained from 3 parallel determinations.

Determination of total flavonoid content: Total flavonoid content was determined using a spectrophotmetric method based on formation of flavonoid complex with aluminum [18]. Total flavonoid content was calculated as catechin (mgCE/100g) using the equation based on the calibration curve. 
Determination of the total monomeric anthocyanins: The total monomeric anthocyanin content in the plant extracts was determined using the $\mathrm{pH}$-differential method previously described [19]. The result, taken as the monomeric anthocyanin pigment (MAP), was expressed as $\mathrm{mg}$ of cyanidin-3-0-glucoside $\mathrm{dm}^{-3}$.

Determining the mass of dry residue: Mass of the dry residue obtained by the tested extracts was taken by 20 $\mathrm{mL}$ each of the extract and the evaporation is carried out to dryness.

\section{Results and discussions}

Extracts of black mulberry fruit prepared by maceration and ultrasonic extraction with ethanol-water system of different concentrations, at constant solvomodulu (fruitsolvent 1:10). Maceration process lasted 15, 30, 60, 120 and $240 \mathrm{~min}$. Figure 1 shows the change in weight of the dry residue of the extractin time with different proportions of ethanol in the mixture obtained by maceration and ultrasonic extraction.

Weight of dry residue ranges from $1.20 \mathrm{~g} / 10 \mathrm{~g}$ in ethanol $80 \%$ after 15 min to $3.05 \mathrm{~g} / 10 \mathrm{~g}$ extraction in ethanol $40 \%$ after 240 min of extraction by maceration. With increasing time of extraction increases the yield. The change in yield of between 120 and 240 minutes is minimal and therefore the optimum time, as well as maceration may take 120 minutes.

Applying ultrasonic extraction, the weight of the dry residue ranges from 1.50 to $3.25 \mathrm{~g} / 10 \mathrm{~g}$ in $80 \%$ ethanol, after $15 \mathrm{~min}$, and $40 \%$ ethanol for 240 minutes after the extraction, respectively. From Figure 1 it can be seen that the optimal time of ultrasonic extraction is 120 minutes while the highest yield. After that, the yield was increased more slowly. Figure 2 shows the dependence of the weight of the dry residue of the share of ethanol in the solvent for the different time of maceration and ultrasonic extraction.

From figure 2 it is clear that the most suitable system for the extraction of a mixture of ethanol-water with the $60 \%$ ethanol content, except for the current extraction process (15 min). For modeling the kinetics of extraction from black mulberry fruit was used the model based on the unsteady diffusion. Kinetic equation and linear transforamtions are shown in the following expressions [20]:

$$
\begin{gathered}
q_{i} / q_{0}=(1-b) \cdot e^{-k t} \\
\ln \left(q_{i} / q_{0}\right)=\ln (1-b)-k t
\end{gathered}
$$

where is: $\mathrm{q}_{0}$-amount of the extractive substances present in the fruit at the start,

q- amount of the extractive substances after a certain time of extraction,

b-coefficient of rapid extraction, k-coefficient of slow extraction.

In table 1 are shown the values of the coefficients $\mathrm{k} i \mathrm{~b}$ in the equations of kinetics of extraction.

The highest value of coefficient $k$ is achieved with $40 \%$ ethanol solution for ultrasonic extraction (0.0053) and the lowest was in $60 \%$ ethanol solution, also for ultrasonic extraction (0.0006). The coefficient of rapid extraction (b) were ranged from 0.4105 for ultrasonic extraction in $80 \%$ ethanol to 0.7768 for maceration in $40 \%$ solution of ethanol.

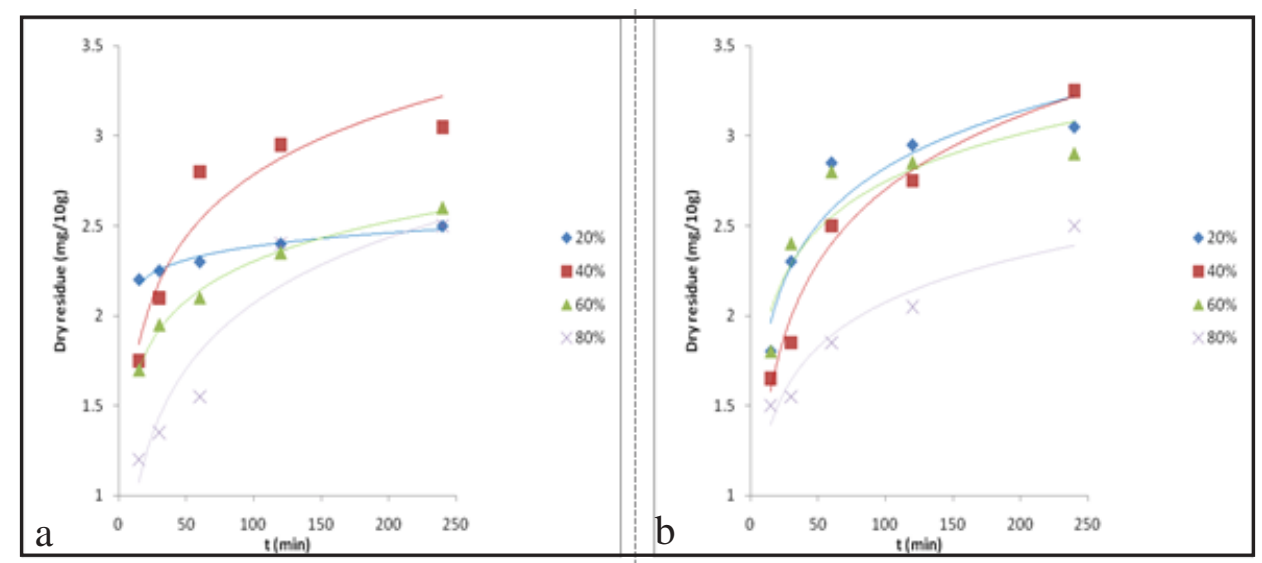

Fig. 1. The change in weight of the dry residue of the extract in time with different proportions of ethanol

in the mixture obtained by a) maceration b) ultrasonic extraction

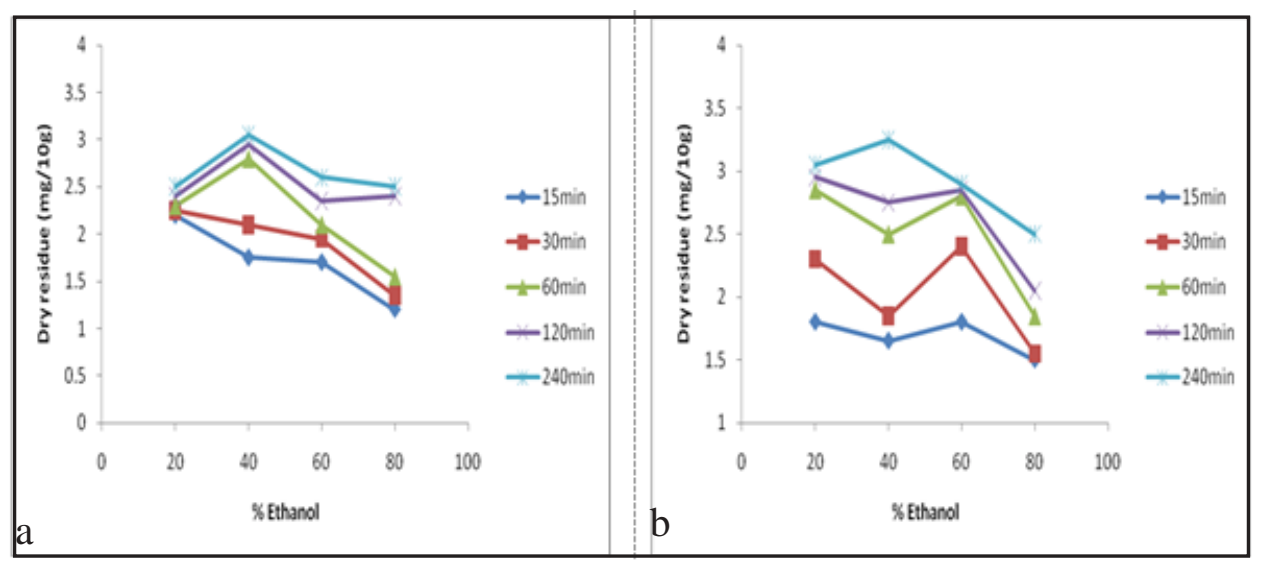

Fig. 2. The dependence of the weight of the dry residue of the share of ethanol in the solvent for the different time of a) maceration b)ultrasonic extraction

Table 1

THE VALUES OF THE COEFFICIENTS $\mathrm{k} i \mathrm{~b}$ 
In figure 3 is shown the dependence of the contents of total phenols in ethanol-aqueous extracts of mulberry fruit in time with different concentration of ethanol. Total phenol content was expressed as mg gallic acid equivalents (GAE) per $100 \mathrm{~g}$ of fruit.

The investigation of the kinetics of extraction of total extractives can be seen that grows over time yields total extractives. After the extraction time of $120 \mathrm{~min}$ the yield of total phenols increase in the time up to $240 \mathrm{~min}$ by slowly increasing. Therefore, the extraction time of 120 min can be taken as the optimum time for extraction. There are two periods of increase in the yield of total extractives: fast and slow extraction period.

During periods of rapid extraction up to $60 \mathrm{~min}$. In the period of rapid extraction washing and dissolving the extractive matter from the surface of the destroyed cells of plant material extracted more than $90 \%$ of total phenols. It shows that the fragmentation of the plant material used for the tests is relatively high, and that a high degree of destruction of cells.

Based on these results, we concluded that the optimum extraction time is $60 \mathrm{~min}$, because the subsequentincrease in the content of phenolic compounds in the extracts slightly, but significantly extends the extraction process. The level of total phenol extraction after one hour in all cases greater than $90 \%$.

In figure 4 is shown the dependence of the content of phenolic compounds according to the share of ethanol in the mixture for extraction, in different time intervals.

From Figure 4a we can see that the most suitable system for the extraction of ethanol-water mixture with the ethanol content to $60 \%$. From figure $4 \mathrm{~b}$ we can see that the most suitable system for the extraction of the one in which the ethanol content to $60 \%$. The content of total phenolics in the extracts tested ranges from 60 to $152 \mathrm{mgGAE} / 100 \mathrm{~g}$ fresh fruit. The highest content of total phenolics in the extracts obtained using a solvent system ethanol-water$\mathrm{HCl}(60: 39: 1)$. The differences in total phenol content of different composition are a consequence of the extraction of different polarity of applied solvent system.
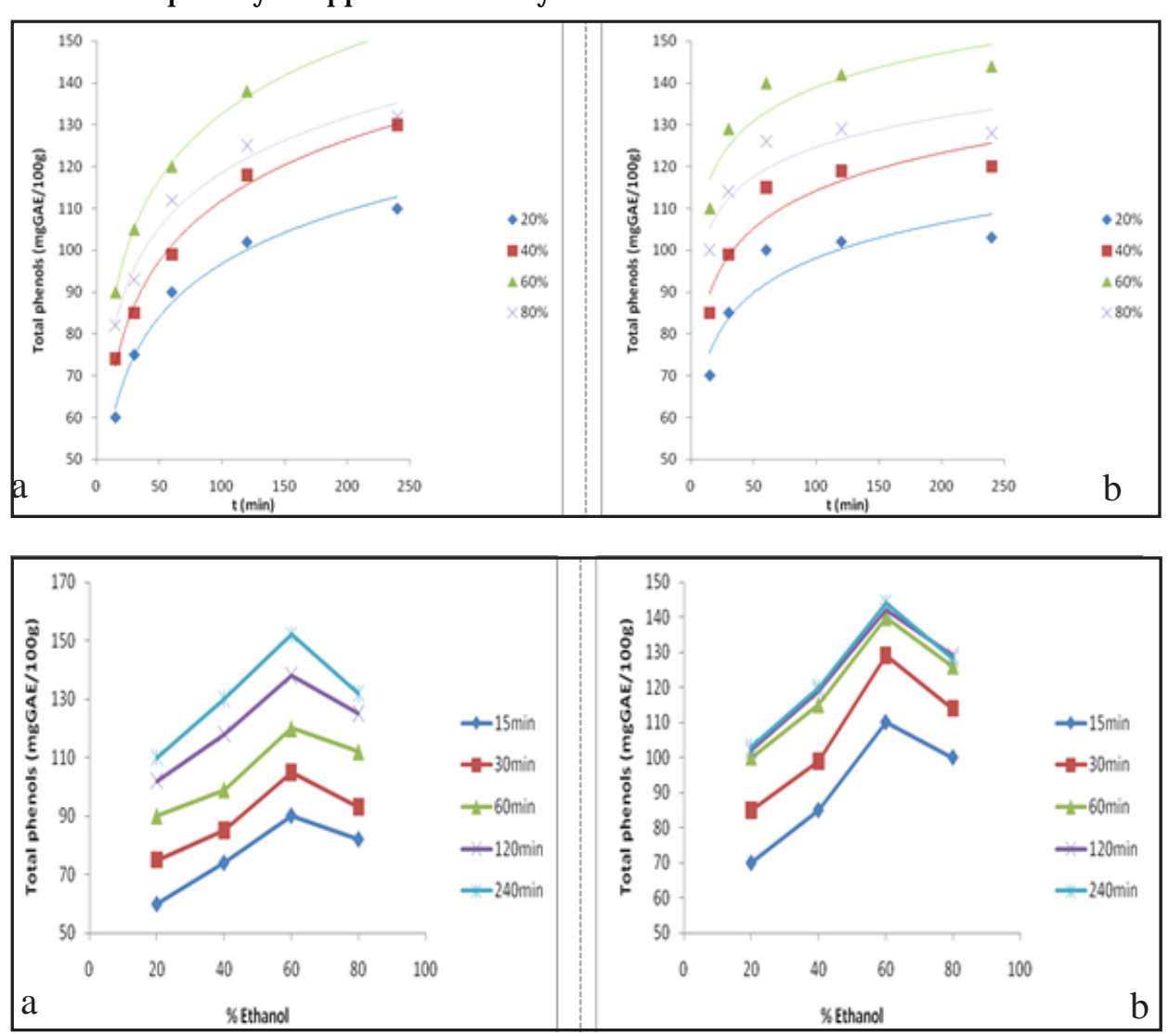

REV.CHIM. (Bucharest) $70 \diamond$ No. $3 \bullet 2019$

http://www.revistadechimie.ro
In the maceration extraction after extraction time of 120 min increase yields of total phenols during the 240 min is insignificant. Therefore, in this case the extraction time of 120 min can be taken as the optimum time for extraction.

The same procedure was applied in investigating the ultrasonic extraction of phenolic compounds from black mulberry. Rapid extraction time period is $60 \mathrm{~min}$. In the period of rapid extraction washing and dissolving the extractive matter from the surface of the destroyed cells of plant material extracted up to $90 \%$ of total phenols. It shows that the fragmentation of the plant material used for the tests is relatively high, and that a high degree of destruction of cells. The extraction process with ultrasonic mixing is much more efficient than extraction by maceration. The results show that the effect of ultrasound has a positive effect on the rate of extraction of phenolic compounds from the fruit of mulberry. Ultrasound extraction, at $25^{\circ} \mathrm{C}$ is obtained a higher vield of total phenols in the mulberry fruitcompared to maceration twice shorter period of time, under the same conditions (ethanol concentration, and solvomodul). Under the influence of ultrasound increases the yield of total phenols in much shorter time period. The most likely mechanism of action of ultrasonic is intensifying mass transfer and easier penetration of the solvent into the cells of the plant material. In classical maceration over the normal mechanism of diffusion through the cell walls, and therefore this process requires a much longer extraction time [21].

The results that were similar to the results presented in this paper were obtained in the study of the extraction process nettle leaf mixtures of ethanol-water [22].

Comparing our results with studies by other researchers, we can conclude that the ethanol extract of black mulberry in Turkey contains a slightly larger amount of phenolic compounds (169 mgGAE/100g) [23]. Larger amounts of total phenolics showed the fruit of the black mulberry tree, which is harvested in Brazil (373 mgGAE/100g) [24], while a significantly higher content of phenol containing ethanol
Fig. 3. Dependence of total phenol content of the mulberry extracts in time obtained by a) maceration b) ultrasonic extraction for different shares of ethanol in the mixture

Fig. 4. The dependence of the content of phenolic compounds according to the share of ethanol in

the mixture for extraction, in different time intervals 


\begin{tabular}{|c|c|c|c|c|}
\hline \multicolumn{5}{|c|}{ Total phenols } \\
\hline & \multicolumn{2}{|c|}{ Maceration } & \multicolumn{2}{|c|}{ Ultrasonic extraction } \\
\hline Ethanol & k & $\bar{B}$ & $\mathrm{~K}$ & $\mathrm{~b}$ \\
\hline $20 \%$ & 0.0014 & 0.4864 & 0.0002 & 0.6009 \\
\hline $40 \%$ & 0.0028 & 0.5110 & 0.0005 & 0.6907 \\
\hline $60 \%$ & 0.0048 & 0.5999 & 0.0010 & 0.8374 \\
\hline $80 \%$ & 0.0020 & 0.6125 & 0.0002 & 0.7641 \\
\hline
\end{tabular}

Table 2

THE VALUES OF KINETICS PARAMETERS FOR TOTAL PHENOLICS EXTRACTION

extract of the fruit of the black mulberry tree, which is harvested in Korea ( $867 \mathrm{mgGAE} / 100 \mathrm{~g}$ ) [25]. The differences in the content of phenolic compounds may be due to the area where the timber is grown, the climate, land, used solvent for extracting as well as the type of extraction. The values of coefficinets $k \mathrm{i} b$ are shown in table 2. The values of coefficientk are higher for maceration than ultrasonic extraction in all of used solutions of ethanol, while the coefficient $b$ is higher for ultrasonic extraction. The highest values was in $60 \%$ solution of ethanol (0.8374).

In figure 5 is shown the dependence of the contents of flavonoids in extracts in time with different contents of ethanol obtained by maceration and ultrasonic extraction. The flavonoid content is expressed as mg catechin equivalents (CE) per $100 \mathrm{~g}$ of fruit.

The flavonoid content of extract obtained by maceration is ranged from 60.02 to $81.45 \mathrm{mgCE} / 100 \mathrm{~g}$. Based on the results it can be seen that the optimal solvent is $60 \%$ ethanol solution in which the yield of flavonoids for all time greatest. After the extraction by maceration extraction time of 120 minutes an increase in the yield of flavonoids for the time to $240 \mathrm{~min}$ is slower. Therefore, as the optimum time may be taken during $120 \mathrm{~min}$.
The ultrasonic extraction for the extraction of flavonoids, the flavonoids content ranging from 52.73 to $113 \mathrm{mgCE} /$ $100 \mathrm{~g}$. Based on the obtained results it can be concluded that the optimal conditions for ultrasonic extraction of 120 minutes, after which the yield increases slightly, and the use of $60 \%$ ethanol solution for extraction when the yield for all time greatest extraction. The application of ultrasonic extraction increases the yield of flavonoids in the tested extracts. Figure 6 . shows the dependence of the contents of flavonoids of the stake in a mixture of ethanol for the extraction by maceration for different times of extraction.

The optimal solvent for the extraction of flavonoids is $60 \%$ ethanol. Table 3 shows the values of coefficients $\mathrm{k} i \mathrm{~b}$.

The values of coefficient $b$ are similar for maceration and ultrasonic extraction. The coefficient of rapid extraction was the highest in $40 \%$ ethanol solution for ultrasonic extraction. The highest values of coefficient $k$ was in $60 \%$ ethanol solution for ultrasonic extraction.

In figure 7 is shown the dependence of the content of the monomeric anthocyanins with maceration time and ultrasonic extraction for different compositions of the mixture for extraction. The content of anthocyanin expressed as mg of cyanidin-3-0-glucoside per $100 \mathrm{~g}$ of the fruit.
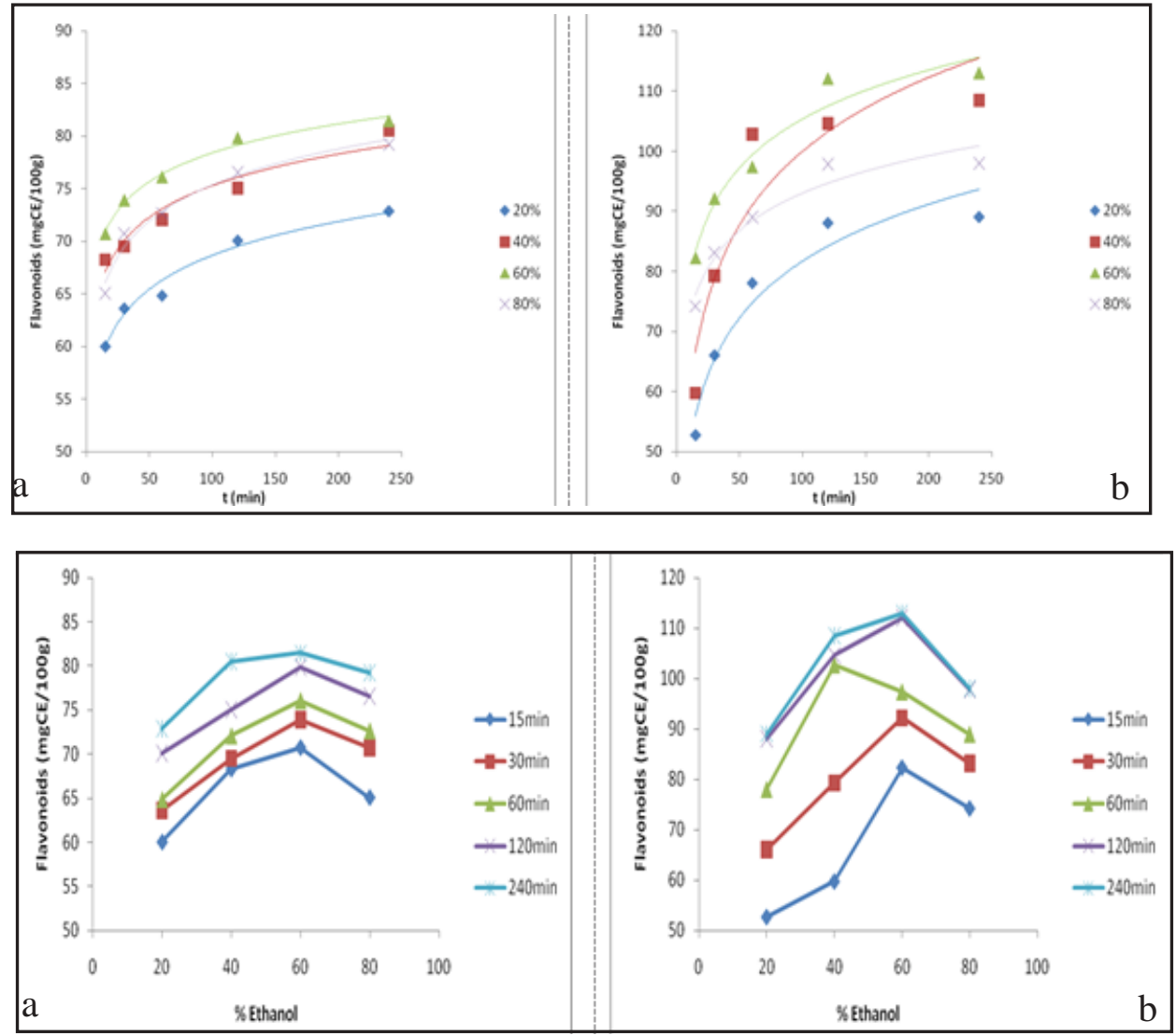

b
Fig. 5. The dependence of the contents of flavonoids in extracts in time with different contents of ethanol obtained by a) maceration b) ultrasonic extraction
Fig. 6. The dependence of the contents of flavonoids of the stake in a mixture of ethanol for the extraction by a) maceration b) ultrasonic extraction for different times of extraction

\begin{tabular}{|c|c|c|c|c|}
\hline \multicolumn{5}{|c|}{ Flavonoids } \\
\hline & \multicolumn{2}{|c|}{ Maceration } & \multicolumn{2}{c|}{ Ultrasonic extraction } \\
\hline Ethanol & $\mathrm{k}$ & $\mathrm{B}$ & $\mathrm{K}$ & $\mathrm{B}$ \\
\hline $20 \%$ & 0.0017 & 0.6719 & 0.0012 & 0.5950 \\
\hline $40 \%$ & 0.0028 & 0.7257 & 0.0013 & 0.7735 \\
\hline $60 \%$ & 0.0026 & 0.7663 & 0.0032 & 0.7414 \\
\hline $80 \%$ & 0.0020 & 0.7557 & 0.0012 & 0.6843 \\
\hline
\end{tabular}

Table 3

THE VALUES OF THE COEFFICIENTS $k$ i b FOR FLAVONOIDS EXTRACTION 


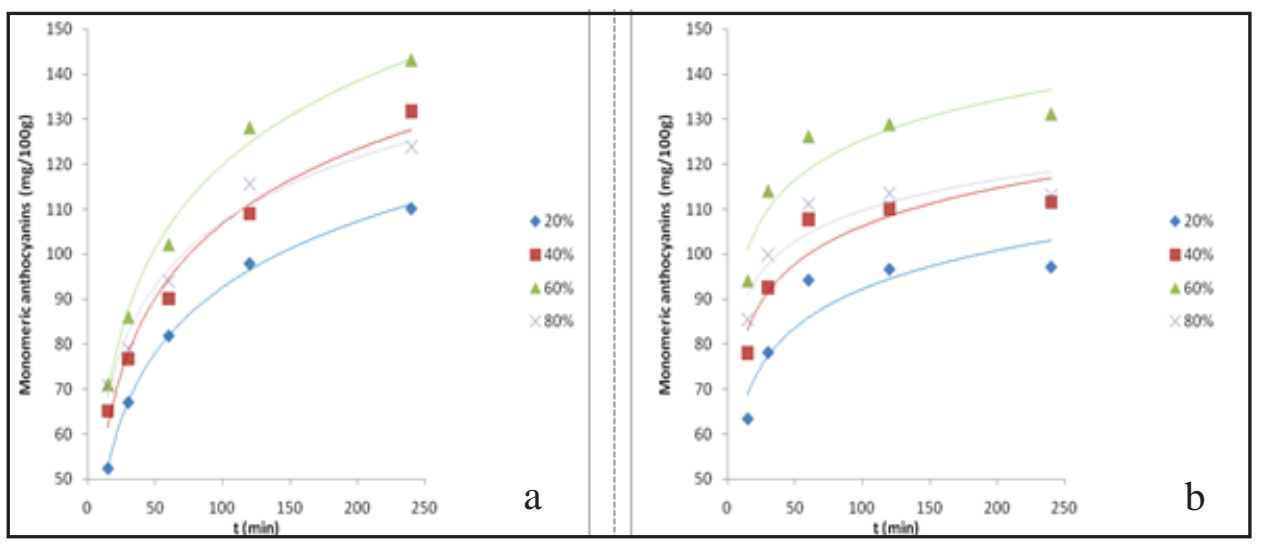

Fig. 7. The dependence of the content of anthocyanins in time for extract mulberry obtained by a) maceration b) ultrasonic extraction for different shares of ethanol in the mixture

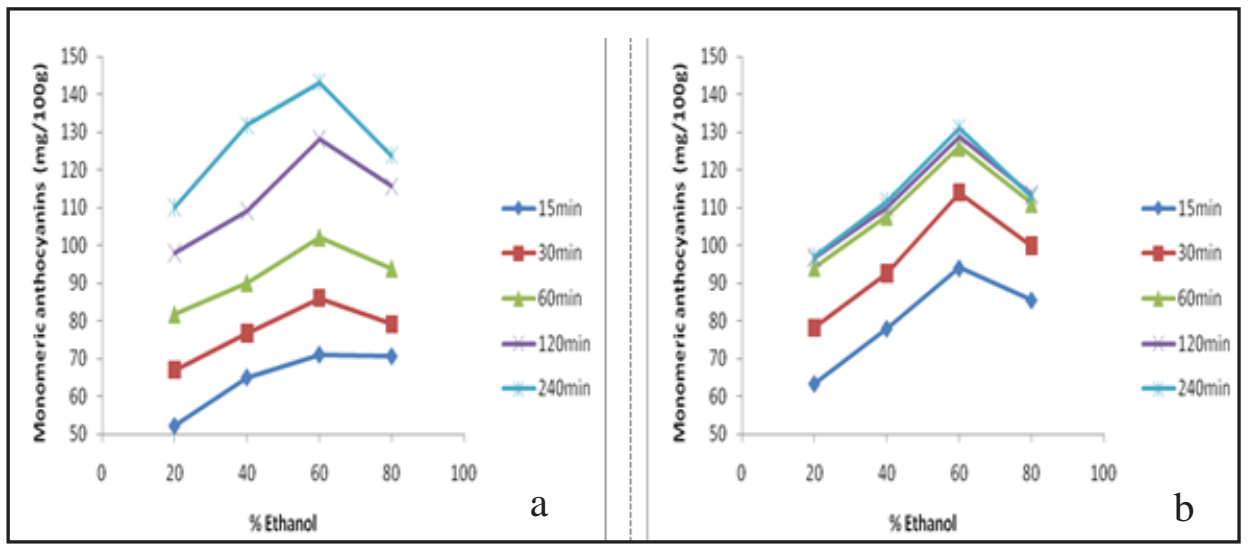

Fig. 8. The dependence of the content of monomeric anthocyanins according to the share of ethanol in the mixture for a) maceration $b$ ) ultrasonic extraction, in different time intervals.

Anthocyanin content of the extracts obtained by the process of maceration ranges from 2.30 to 143.18 mgcy3-0-glu/100g. Based on these results, it can be concluded that the optimal time for extraction of monomeric anthocyanins is $120 \mathrm{~min}$. After this time, the content of anthocyanins in the tested extracts was slowly increases. In figure 8 is shown the dependence of the content of anthocyanins in the extract obtained by maceration of the content of ethanol in the mixture for extraction of different extraction time.

The optimal solvent for the extraction is $60 \%$ ethanol. Anthocyanin content of the extracts obtained by the method of ultrasonic extraction ranges from 63.40 to $131.11 \mathrm{mg}$ of Cy-3-0-glucoside/100g. The values of coefficinets $\mathrm{k} i \mathrm{~b}$ are shown in table 4.

Table 4

THE VALUES OF THE COEFFICIENTS $k$ i b FOR ANTHOCYANINS EXTRACTION

\begin{tabular}{|c|c|c|c|c|}
\hline \multicolumn{5}{|c|}{ Monomeric anthocyanins } \\
\hline & Maceration & Ultrasonic extraction \\
\hline Ethanol & $k$ & $\mathrm{~B}$ & $\mathrm{~K}$ & $\mathrm{~B}$ \\
\hline $20 \%$ & 0.0000 & 0.3443 & 0.0007 & 0.4177 \\
\hline $40 \%$ & 0.0000 & 0.3410 & 0.0013 & 0.4225 \\
\hline $60 \%$ & 0.0010 & 0.8121 & 0.0032 & 0.7313 \\
\hline $80 \%$ & 0.0010 & 0.4013 & 0.0002 & 0.4911 \\
\hline
\end{tabular}

The highest value of coefficient $\mathrm{k}$ was in $60 \%$ ethanol solution for ultrasonic extraction (0.0032) and the highest value of coefficient b was, also in $60 \%$ solution of ethanol, for maceration.

The fragmentation of plant material used for testing is relatively high. A high degree of destruction of cells increases the surface area from which in a rapid period washed down quickly dissolve extractive matter and thus provides a high level of their extraction in this period.

In a period of rapid extraction ( $120 \mathrm{~min}$ ), by maceration, was extracted $78.60 \%$ total extractive matter, $86.89 \%$ of total phenolic compounds, $85.22 \%$ of flavonoids and $75.51 \%$ of anthocyanins. The period of rapid extraction byultrasonic extraction was 120 min for dry residue and flavonoids ( 85.33 and $86.23 \%$, respectively) and $60 \mathrm{~min}$ for total phenolic (81.95\%) and anthocyanins (86.07\%).

The value of coefficient $b$ is higher for ultrasonic extraction for dry residue and total phenolics, while for flavonoids and anthocyanins the values of coefficient $b$ are similar for maceration and ultrasonic extraction. The reason for this is most likely facilitates the penetration of the solvent into particles of the plant material, increasing the speed of mass transfer and destruction plantcells under the influence of ultrasound. The influence of other factors can not easily be seen, because it is too complex and

Table 5

THE FAST EXTRACTION TIME, EXTRACTION LEVEL IN THE FAST EXTRACTION TIME AND THE VALUES OF b AND k COEFFICIENTS

\begin{tabular}{|c|c|c|c|c|c|c|c|c|}
\hline & \multicolumn{4}{|c|}{ Maceration } & \multicolumn{4}{|c|}{ Ultrasonic extraction } \\
\hline & PBE, min & $\mathrm{SE}, \%$ & $\mathrm{k}$ & $B$ & $\mathrm{PBE}, \mathrm{min}$ & $\mathrm{SE}, \%$ & $\mathrm{k}$ & B \\
\hline Dry residue & 120 & 78.60 & $0.0024^{-}$ & 0.5462 & 120 & 85.33 & 0.0006 & $0.7408^{--}$ \\
\hline Total phenolic & 120 & 86.89 & 0.0048 & 0.5999 & $60^{-}$ & 81.95 & 0.0010 & 0.8374 \\
\hline Flavonoids & 120 & 85.22 & 0.0026 & 0.7663 & 120 & 86.23 & 0.0032 & 0.7414 \\
\hline Anthocyanins & 120 & 75.51 & $0.0010^{-}$ & $0.8121^{-}$ & 60 & 86.07 & 0.0032 & $0.7313^{-}$ \\
\hline
\end{tabular}


probably combined with the influence of mixing extraction ultrasound system. The value of coefficient $k$ was ranged from 0.0010 to 0.0048 for maceration. An ultrasonic extraction coefficient $\mathrm{k}$ ranging from 0.0006 to 0.0032 .

\section{Conclusions}

The highest content of total phenolics in the extracts obtained using the solvent system ethanol-water- $\mathrm{HCl}$ (60:39:1) in both the extraction process. The differences in the content of total phenols in different compositions of the mixture for extraction are the result of different polarity of the applied solvent systems. Based on the results show that the optimal solvent $60 \%$ ethanol solution in which the yield of flavonoids for all time greatest, both for the extraction process. On extraction maceration optimum extraction time is $120 \mathrm{~min}$, and an ultrasonic extraction was $60 \mathrm{~min}$. The flavonoid content of the extracts are prepared by extracting the ultrasound is increased. The optimal time for the extraction of anthocyanins maceration is $120 \mathrm{~min}$, while the optimal time for the extraction of ultrasound for $60 \mathrm{~min}$. The most appropriate solvent is one that contains $60 \%$ ethanol when the highest yield. The results show that the effect of ultrasound has a positive effect on the rate of extraction of phenolic compounds from the fruit of mulberry. Under the influence of ultrasound increases the yield of total phenols in a significantly shorter period of time. The results indicate a high content of phenolic compounds and high antioxidant activity of black mulberry located in Southeast Serbia, which confirms their nutritional and pharmacological potential of this fruit.

Acknowledgements: Financial support of this work by the Serbian Ministry of Education and Science, Project No. ON 172047.

\section{References}

1.C. RICHTER, J PARK, B Ames, Normal oxidative damage to mitochondrial and nuclear DNA is extensive, PNAS (1988).

2.M. Ozgen, S. Serce, K. Kaya, Sci.Hortic, 119, 2009, p.275

3.G. MILIAUSKAS, P. VENSKUTONIS, T. BEEK, Food Chem, 85, 2004, p.231
4.E. CIESLIK, A. GRADA, W. ADAMUS, Food Chem, 94, 2003, p. 135. 5.A. SASS-KISS, J. KISS, P. MILOTA, M. KEREK, M. TOTH-MARKUS, Food Res Inter, 38, 2005, p.1023

6.J. QUIAN, D. LIU, A. HUANG, Food Chem, 87, 2004, p.283

7.A. TRAPPEY, A. BAWADI, R. BANSODE, N. LOSSO, Food Chem, 91, 2005, p.665.

8.J. LIN, C. TANG, Food Chem,101, 2007, p.140.

9.S. ERICSLI, E. ORHAN, Sci Hortic, 116, 2008, p.41.

10.D. GERASOPOULOS, G. STAVROULAKIS, J Sci Food Agric, 73, 1997, p.251.

11.LJ. STANOJEVIC, M. STANKOVIC, V. VELJ KOVIC, M. CAKIC, V. NIKOLIC, D. ILIC, Zbornik radova Tehnološkog fakulteta u Leskovcu, 20,2011, p. 125.

12.LJ . STANOJ EVIC, M. STANKOVIC, LJ . NIKOLIC, V. NIKOLIC, CI\&CEQ, 13, 2007, p.199 (2007).

13. LJ.P. STANOJ EVIC, M.Z.STANKOVIC, M.D. CAKIC, V.D. NIKOLIC, LJ .B. NIKOLIC, D.P. ILI/E, Hem. ind., 63, 2009, p.79

14.V. SINGELTON., J. ROSSI, Am. J. Enol. Viticult., 16,1965, p. 144.

15.J. DEAN, Extraction Techniques in Analytical Sciences, WILEY, 2009, p.49.

16.M. IMRAN, H. KHAN, M. SHAH, R. KHAN, F. KHAN, J . Zheijang Univ.Sci. B, 11, 2011, p.973.

17.M. VINATORU, Ultrason. Sonochem., 8,2001, p. 303

18.A. ORDON, J. GOMEZ, M. ATTU, M. ISLA, Food Chem, 97, 2006, p.452.

19.M. GUISTI, R. WROLSTAD, Characterization and Measurement of Anthocyanins by UV Visible Spectroscopy. Current Protocols in Food Analytical Chemistry. John Wiley and Sons, New York, (2003).

20.V. VELJ KOVIC, D. MILENOVIC, Hem. Ind., 56, 2002,p .60

21.M. VINATORU, M. TOMA, O. RADU, P. FILIP, D. LAZURCA, T. MASON, Ultrason. Sonochem., 4, 1997, p.135.

22.A. ZDRAVKOVIC, M. CAKIC, LJ. STANOJEVIC, V. NIKOLIC, M. STANKOVIC, LJ . NIKOLIC, D. ILIC, Sav. Tehn., 1, 2012, p.30

23.S. ERCISLI, M. TOSUN, B. DURALIJA, S. VOÆA, M. SENGUL, M. TURAD, Food Tecnol. Biotech., 48, 2010, p.102.

24.N. HASSIMOTTO, M. GENOVESE, F. LAJOLO, Food Sci. Technol. Int., 13, 2007, p.17.

25.W. CHUN W, X. LI, W. YUANCHANG, C. HU, H. XIANZHI, Afr. J. Biotech., 10, 2011, p.16175

Manuscript received: 04.07 .2018 